\title{
Retraction
}

\section{Retracted: Successful Treatment of Refractory Wart with a Topical Activated Vitamin D in a Renal Transplant Recipient}

\author{
Case Reports in Transplantation \\ Received 21 January 2022; Accepted 21 January 2022; Published 23 February 2022 \\ Copyright (C) 2022 Case Reports in Transplantation. This is an open access article distributed under the Creative Commons \\ Attribution License, which permits unrestricted use, distribution, and reproduction in any medium, provided the original work \\ is properly cited.
}

Case Reports in Transplantation has retracted the article titled "Successful Treatment of Refractory Wart with a Topical Activated Vitamin D in a Renal Transplant Recipient" [1], because it contains a duplicated figure with an article published in Journal of Dermatology [2]. It was identified that Figure 1 in [1] appears to be identical to Figure 3 in [2], despite differences in the description of the figures.

The authors were contacted for clarification, but they did not respond. The article is therefore retracted from the journal with the agreement of the Editorial Board due to concerns regarding the reliability of the data.

\section{References}

[1] L. Moscarelli, F. Annunziata, A. Mjeshtri et al., "Successful Treatment of Refractory Wart with a Topical Activated Vitamin D in a Renal Transplant Recipient," Case Reports in Transplantation, vol. 2011, Article ID 368623, 3 pages, 2011.

[2] I. Imagawa and H. Suzuki, "Successful treatment of refractory warts with topical vitamin $\mathrm{D}_{3}$ derivative (maxacalcitol, $1 \alpha, 25$ dihydroxy-22-oxacalcitriol) in 17 patients," Journal of Dermatology, vol. 34, no. 4, pp. 264-266, 2007. 


\title{
Successful Treatment of Refractory Wart with a Topical Activated
} Vitamin D in a Renal Transplant Recipient

\author{
Luciano Moscarelli, Filomena Annunziata, Anduela Mjeshtri, Nunzia Paudice, \\ Aris Tsalouchos, Maria Zanazzi, and Elisabetta Bertoni \\ Renal Unit, Careggi University Hospital, Viale Pieraccini 18, 50139 Florence, Italy
}

Correspondence should be addressed to Luciano Moscarelli, moscarellil@libero.it

Received 17 November 2011; Accepted 26 December 2011

Academic Editor: K. Kawamura

Copyright ( $\odot 2011$ Luciano Moscarelli et al. This is an open access article distributed under the Creative Commons Attribution License, which permits unrestricted use, distribution, and reproduction in any medium, provided the original work is properly cited.

Warts are benign proliferations of the skin and mucosa caused by infection with human papillomavirus. They are commonly treated with destructive modalities such as cryotherapy with liquid nitrogen, local injection of bleomycin, electrocoagulation, topical application of glutaraldehyde, and local and systemic interferon- $\beta$ therapy. These treatment modalities often cause pain and sometimes scarring or pigmentation after treatment. We herein report a case with a right index finger wart, which was successfully treated with a topical activated vitamin D.

\section{Introduction}

Warts are a benign proliferation of the skin and mucosa caused by infection with human papillomavirus (HPV). HPV is ubiquitous, and renal transplant recipients (RTRs) may never totally clear HPV infections, which are the most frequently recurring infections. This infection is important because of its link to the development of certain skin cancers, in particular, squamous cell carcinoma. Regular surveillance, sun avoidance, and patient education are important aspects of the management strategy. Warts are usually treated by traditional destructive modalities such as cryotherapy with liquid nitrogen, local injection of bleomycin, electrocoagulation, topical application of glutaraldehyde, and local and systemic interferon- $\beta$ therapy [1-3]. However, the tolerance of patients to these treatment modalities is poor, because they often cause pain, especially in children, and sometimes scarring or pigmentation after treatment. No treatment has been uniformly effective, and warts are often refractory, especially in immunocompromised patients where their quality of life is threatened. Here, we report an RTR with a right index finger wart, which was successfully treated with a topical activated vitamin D.

\section{Case Report}

A 41-year-old woman with unknown native kidney disease received a renal transplant from deceased donor in January 2009. She was on treatment with immunosuppressive therapy based on tacrolimus, steroid, and mycophenolate mofetil. She presented 19 months after transplantation a wart on right index finger (Figure 1(a)) which obtained partial clearance after 6-month treatment with cryotherapy and elettrocoagulation but it regrew rapidly. We attempted treatment with simple local application of activated vitamin $\mathrm{D}$ (gauze wet with calcitriol $0.5 \mu \mathrm{g}$ solution) at least two times a day (during the morning and the next night). The patient was advised to reapply a gauze wet with calcitriol 0.5 solution after each handwashing. Three months later, the wart disappeared without pain or other side effects (Figure 1(b)), and it has not recurred within the 9 months since the disappeared. The medication was well tolerated. 


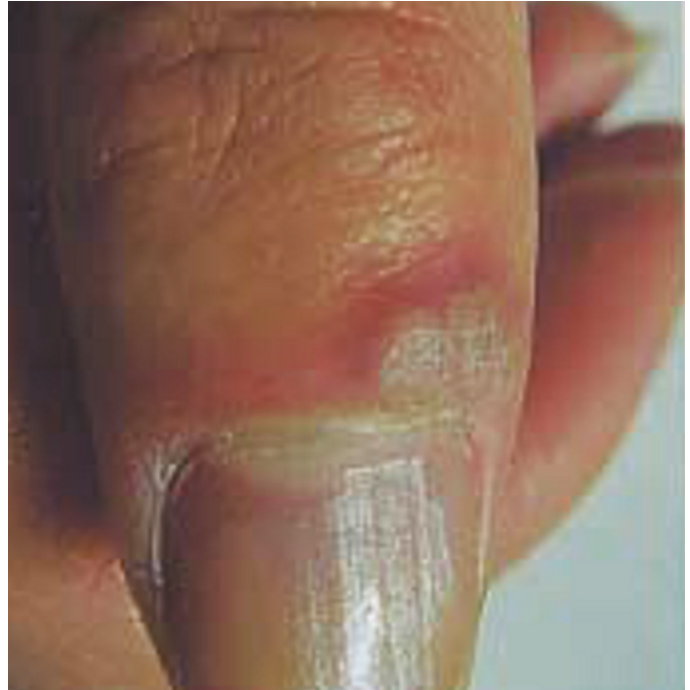

(a)

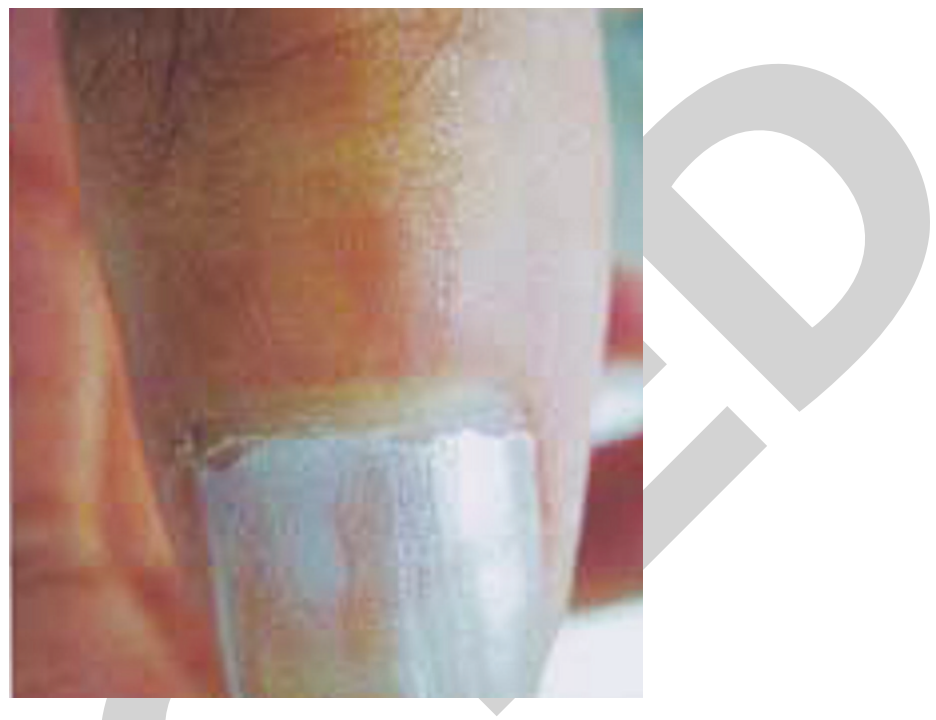

(b)

FIGURE 1: Refractory wart on right index finger (a). It was treated using local application of calcitriol $0.5 \mu \mathrm{g}$ solution and disappeared completely three months later (b).

No adverse effects or abnormal serum test results, including elevated serum calcium level, were observed.

\section{Discussion}

Incidence of warts in RTRs varies from $8 \%$ to $55 \%$ depending on the patient's characteristics, the time since transplantation, and immunosuppressive protocols [4]. Skin biopsy and identifying the type of HPV are required to diagnose precisely. Unfortunately, we could not take biopsies from the affected lesion. Therefore, our diagnosis was only based on the clinical appearance. The vitamin D system has multiple physiological and pharmacological effects mediated by action of the vitamin D receptors (VDRs). Recently, VDR activators (VDRAs) have been shown to inhibit cell replication and have immunomodulatory properties. An important observation was reported which suggested that toll-like receptor (TLR) activation of human macrophages upregulated expression of vitamin $\mathrm{D}$ receptor and vitamin D-1-hydroxylase genes, leading to induction of the antimicrobial peptide [5]. This suggests an association of TLRs and vitamin-D-mediated innate immunity [5]. Previously the topical application of vitamin $\mathrm{D}$ derivatives has become a first-line therapy in the routine treatment of chronic plaque psoriasis as well as for palmoplantar keratosis [6]. A combination of isotretinoin and calcitriol has been reported as the most effective therapy for HPV-associated precancerous and cancerous skin lesions [7]. The effect of vitamin D derivatives was speculated to be derived from its potential to regulate epidermal cell proliferation and differentiation and to modulate cytokine production [8]. Our case report demonstrates for the first time to our knowledge that local application of activated vitamin D is an effective and welltolerated supplementary treatment of recalcitrant wart. A new focus of interest is the levels of activated vitamin $\mathrm{D}$ to be reached, particularly in relation to local cellular growth regulation [9]. These levels may provide an explanation for the striking effect of the activated vitamin D and the minimal effect of its the simple application seen in this study. In spite of the proposed mechanisms, any treatment of warts may be confounded by a potent placebo effect. Hence, we realize the need for further placebo-controlled studies before any final conclusions can be reached. However, the lack of regression of the wart before being treated by other modality in the same patient seems to suggest a local rather than a systemic or placebo effect.

\section{References}

[1] J. C. Sterling, S. Handfield-Jones, and P. M. Hudson, "Guidelines for the management of cutaneous warts," British Journal of Dermatology, vol. 144, no. 1, pp. 4-11, 2001.

[2] J. P. Allam, T. Hagemann, T. Bieber, and N. Novak, "Successful treatment of therapy-resistant plantar verrucae vulgares with systemic interferon- $\beta$," Journal of Dermatology, vol. 31 , no. 7 , pp. 582-583, 2004.

[3] S. Gibbs, I. Harvey, J. Sterling, and R. Stark, "Local treatments for cutaneous warts: systematic review," British Medical Journal, vol. 325, no. 7362, pp. 461-464, 2002.

[4] I. Blohme and O. Larko, "Skin lesions in renal transplant patients after 10-23 years of immunosuppressive therapy," Acta Dermato-Venereologica, vol. 70, no. 6, pp. 491-494, 1990.

[5] P. T. Liu, S. Stenger, H. Li et al., "Toll-like receptor triggering of a vitamin D-mediated human antimicrobial response," Science, vol. 311, no. 5768, pp. 1770-1773, 2006.

[6] J. N. W. N. Barker, R. E. Ashton, R. Marks, R. I. Harris, and J. Berth-Jones, "Topical maxacalcitol for the treatment of psoriasis vulgaris: a placebo- controlled, double-blind, dose-finding study with active comparator," British Journal of Dermatology, vol. 141, no. 2, pp. 274-278, 1999.

[7] S. Majewski, M. Skopinska, W. Bollag, and S. Jablonska, "Combination of isotretinoin and calcitriol for precancerous 
and cancerous skin lesions," The Lancet, vol. 344, no. 8935, pp. 1510-1511, 1994.

[8] K. Egawa and T. Ono, "Topical vitamin D3 derivatives for recalcitrant warts in three immunocompromised patients," British Journal of Dermatology, vol. 150, no. 2, pp. 374-376, 2004.

[9] J. E. Osborne and P. E. Hutchinson, "Vitamin D and systemic cancer: is this relevant to malignant melanoma?" British Journal of Dermatology, vol. 147, no. 2, pp. 197-213, 2002. 